\title{
Application of kenaf seed oil-nanostructured lipid carrier into palm-based $\alpha$-tocopherol cream for photoprotection
}

\author{
Chee Chin Chu ${ }^{1}$, Zafarizal Hassan ${ }^{2}$, Chin Ping Tan $^{3}$, and Kar Lin Nyam ${ }^{1}$ \\ ${ }^{1}$ Affiliation not available \\ ${ }^{2}$ Malaysian Palm Oil Board \\ ${ }^{3}$ Universiti Putra Malaysia
}

July 6, 2020

\begin{abstract}
The application of nanostructured lipid carrier (NLC) in UV filters encapsulation was found to enhance its safe use. In this work, kenaf seed oil-NLC (KSO-NLC) co-loaded with UV filters encapsulated was used as an active ingredient in $\alpha$-tocopherol cream to develop a photoprotective prototype. It was then subjected to further analysis to determine the physical properties storage stability and cytotoxicity. The ratio of KSO-NLC to $\alpha$-tocopherol cream was optimised based on the SPF value using UV transmittance analyser. The physical properties of the samples were analysed and the amount of $\alpha$-tocopherol was quantified by ultra-high performance liquid chromatography (UHPLC). The optimised sample was then evaluated for in vitro antioxidant activities using DPPH and ABTS assays. Meanwhile, in vitro cytotoxicity was studied on normal human dermal fibroblast (NHDF) cell line using MTT and CCK-8 assays. The sample produced by KSO-NLC to $\alpha$-tocopherol cream in ratio 1:2 (N3) showed SPF value $>50$. Besides, the samples showed microbial stability and sustainable $\alpha$-tocopherol content upon 12 weeks of storage. The cytotoxicity evaluation of N3 and $\alpha$-tocopherol cream (N5) showed $>100 \%$ cell proliferation indicated there is no side effect on the cell growth, yet it triggered the cell proliferation with the presence of bioactive compounds. Overall, the results herein gathered are very promising towards the development of new green cosmetic formulations with the utilisation of KSO-NLC and palm-based $\alpha$-tocopherol cream.
\end{abstract}

\section{Hosted file}

Manuscript-part 3 JAOCS.docx available at https://authorea.com/users/340250/articles/467346application-of-kenaf-seed-oil-nanostructured-lipid-carrier-into-palm-based-\%CE\%B1tocopherol-cream-for-photoprotection 